\title{
Work in Progress: Developing a Quantitative Instrument for Measuring Un- dergraduate Engineering Students' Future Time Perspectives
}

\section{Catherine McGough, Clemson University}

Catherine McGough is currently a graduate research assistant in Engineering and Science Education at Clemson University. She obtained her B.S. in Electrical Engineering from Clemson University in 2014. Her research interests are in undergraduate engineering student motivations and undergraduate engineering problem solving skill development and strategies.

\section{Adam Kirn, University of Nevada, Reno}

Adam Kirn is an Assistant Professor of Engineering Education at University of Nevada, Reno. His research focuses on the interactions between engineering cultures, student motivation, and their learning experiences. His projects involve the study of student perceptions, beliefs and attitudes towards becoming engineers, their problem solving processes, and cultural fit. His education includes a B.S. in Biomedical Engineering from Rose-Hulman Institute of Technology, a M.S. in Bioengineering and Ph.D. in Engineering and Science Education from Clemson University.

\section{Dr. Lisa Benson, Clemson University}

Lisa Benson is an Associate Professor of Engineering and Science Education at Clemson University, with a joint appointment in Bioengineering. Her research focuses on the interactions between student motivation and their learning experiences. Her projects involve the study of student perceptions, beliefs and attitudes towards becoming engineers and scientists, and their problem solving processes. Other projects in the Benson group include effects of student-centered active learning, self-regulated learning, and incorporating engineering into secondary science and mathematics classrooms. Her education includes a B.S. in Bioengineering from the University of Vermont, and M.S. and Ph.D. in Bioengineering from Clemson University. 


\title{
Work in Progress: Developing a Quantitative Instrument for Measuring Undergraduate Engineering Students' Future Time Perspectives
}

\begin{abstract}
The purpose of this work in progress is to refine a quantitative instrument that characterizes undergraduate engineering students based on their future time perspectives (FTPs), or their future goals and how those goals affect actions in the present. Our previous qualitative studies have shown that undergraduate engineering students fit into one of three different characteristic FTP types. Based on key characteristics of the three FTP types identified in our previous studies, we have constructed a survey. The items were adapted from pre-existing surveys, FTP literature, and quotes from participants in our qualitative studies. This study tests the validity and reliability of this survey to answer the research question: How accurately can students be described in terms of their FTP characteristics using a quantitative measure? The validity and reliability testing resulted in 27 quantitative items that describe sophomore and junior engineering students' FTPs. These items will help advance research in student motivation and how that motivation affects their behaviors in the classroom.
\end{abstract}

\section{Introduction}

This work in progress addresses the national need for increased numbers and diversity of engineering graduates ${ }^{1-3}$; with the understanding that attracting and retaining these undergraduate students requires focusing on more than just developing students' technical skills ${ }^{2}$. To understand undergraduate engineering students' motivations for being in engineering, our research group explored short-term, task-specific motivation and long-term motivation, goal orientation, and interest. Our research found that one route that allows us to understand these students' motivations and how they are affecting student behavior is by looking at their longterm goals and their projections into the future. Understanding undergraduate students' motivations and quantitatively capturing students' perceptions of their future can help both instructors and researchers in terms of attracting, retaining and effectively educating undergraduate engineering students.

The purpose of this study is to refine a quantitative instrument that categorizes undergraduate engineering students based on characteristics of their future time perspectives (FTPs). FTP theory focuses on student motivation across time scales; it describes an individual, a structured representation of a student's future which takes into consideration how a student perceives their future, the usefulness of their present tasks in terms of their future, and their ability to make connections between present and future. Our prior studies on undergraduate engineering students' FTP across time scales, in different majors, universities, and year in school have revealed different characteristic FTPs ${ }^{4-7}$. Several quantitative measures for student motivation exist, but these measures do not include, and would benefit from, factors that include these characteristics of students' FTPs. 


\section{Background}

FTP

Literature on the motivational effects of students' FTP emphasizes three dimensions: time orientation, perceived instrumentality, and time attitude ${ }^{8,9}$. Time orientation refers to a person's preference for thinking in the past, future, or present. A future time orientation can be further defined by how far ahead a person tends to think, how far into the future that person is setting goals, and the amount of time that person spends focused on future events. A person's time attitude is how positive or negative their outlook of their future is. And their perceived instrumentality is a more task specific dimension that describes how useful the person perceives a certain task to be in regards to their long-term goals ${ }^{9}$. The task can be related to the future goal because it is a step, or "hurdle ${ }^{10}$," that is needed to reach a long term goal; this is exogenous instrumentality ${ }^{9,10}$. Or the task can be perceived as directly related to the future goal, which is described as endogenous instrumentality ${ }^{9,10}$.

Also situated within FTP literature is an individual's ideas of who they can become, who they want to become, and who they do not want to become in the future. These describe a person's realistic, ideal, and avoided future possible selves, respectively ${ }^{7,9,11}$. These future possible selves motivate and function as incentives for a person's behaviors ${ }^{11}$.

\section{Previous Work}

Our research group has conducted multiple qualitative studies exploring undergraduate engineering students' perceptions of the future. The first qualitative study was an interpretative phenomenology analysis (IPA) ${ }^{7}$; nine sophomore and junior biomedical engineering (BME) and mechanical engineering (ME) students at a southeastern land grant institution were interviewed about their experiences in terms of connecting their future goals to their actions in the present. The themes that emerged from these interviews focused on the range of possible future selves that students described. These themes were then described graphically as being cone-shaped (see Figure 1), where the three axes represent time-orientation, instrumentality, time attitude axis ${ }^{7}$.

The second study was a phenomenography, focusing on the different ways in which students are perceiving the future ${ }^{5-7}$. This study was a continuation of the first, which identified the ways students experienced the characteristics described on the three axes in Figure 1. Sophomore and junior BME and ME students ( $\mathrm{n}=18)$ were interviewed using the refined interview protocol from the first study. Three main categories emerged from this study: 1) "Cake Cone" students had the shortest time-orientation axis, and highest perceived instrumentality axis, and a positive time attitude axis; 2) "Sugar Cone" students had the longest time orientation axis, narrowed perceptions of what is useful for their future, and a positive time attitude axis; and 3) "Waffle Cone" students had a medium time orientation axis, were lowest on the perceived instrumentality axis out of the three cone types, and had a more negative time attitude axis ${ }^{5-7}$. Each of these cone types are described in more detail in Appendix A.

A third study focused on sophomore and junior industrial engineering (IE) students $(n=4)$. This study also found that these students fit in one of these three FTP cone types ${ }^{12}$. And a fourth study 
focused on replicating the results of the previous studies with a new population - freshmen engineering students $(n=7)$ at a western land-grant institution ${ }^{13}$. Again, the three FTP cone types were confirmed $^{13}$.

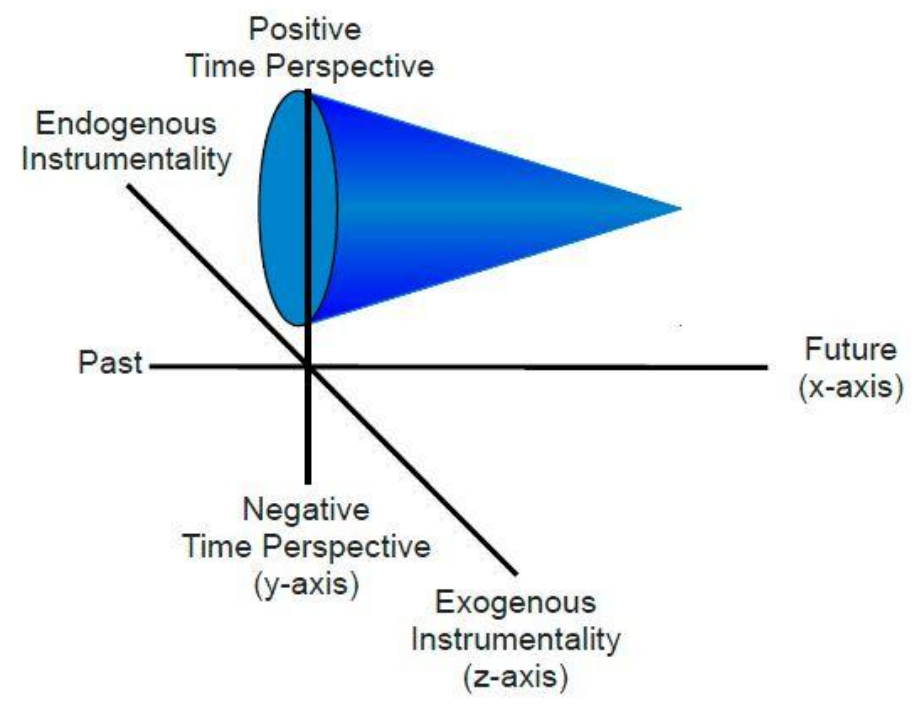

Figure 1: A theoretical characterization of FTP as a "cone" defined on three axes: time orientation (horizontal), time attitude (vertical), and perceived instrumentality (out of plane). This example FTP "cone" shows a student who has a positive time attitude, is future oriented, and has a high instrumentalities in the present task ${ }^{7}$.

While these studies show that the three cone types are consistently being seen in qualitative work, quantitative studies on students' FTP have also shown evidence that three homogenous clusters describing undergraduate engineering students' FTP exist ${ }^{14}$. One study used the Motivations and Attitudes in Engineering (MAE) survey, which our research group adapted from pre-existing validated instruments, including the Motivated Strategies for Learning Questionnaire (MSLQ) ${ }^{15}, \mathrm{FTP}^{10,16}$, and original items written based on goal orientation theory ${ }^{17}$ and FTP theory ${ }^{9,11}$. A k-means cluster analysis of the results of the survey $(n=360)$ showed that three clusters best explained the variability in the data ${ }^{14}$. However, this instrument did not include several characteristics of the FTP cone types identified in our subsequent qualitative work. The study described in this paper attempts to further refine our survey instrument by creating items that quantitatively capture latent constructs reflected in our qualitative findings .

\section{Methods}

Using an instrument in research that does not assess what the researchers are presuming to measure can lead to incorrect results and wrong decisions ${ }^{18}$. In refining the MAE survey, care was taken in the process of choosing factors, developing items, and testing for validity and reliability.

\section{Developing Items}

Factors were chosen based on the results from our previous qualitative research. Code categories that were needed to characterize the three different FTP cone types were used to define our 
factors. Then, an initial pool of items was created for each of the factors by the researcher. The items for this survey were taken from MAE survey and developed from previous qualitative analysis, as described in the background, to create a list of items to choose from, with at least 5 items for each factor ${ }^{5,7,13,14}$. The items are Likert-type on an anchored scale from $0=$ "Strongly Disagree" to 6= "Strongly Agree."

When developing items, there are some characteristics that distinguish "good" items from "bad" items, and these characteristics were mostly related to the clarity of the item ${ }^{18}$. Keeping this distinction in mind, researchers familiar with the project were shown the developed items to check for their clarity in terms of readability, to avoid unnecessarily lengthy items, the use of research terminology, asking two questions with one item, or ambiguous items ${ }^{18}$. Using this process, the item pool was narrowed down to about five items per factor that reflected the scale's purpose.

\section{Validity and Reliability Testing}

After the items were developed, they were tested for content validity, or how well the items reflect the intended factors ${ }^{18}$, using feedback from experts in the field and focus groups with the target population of sophomore undergraduate engineering students. The item pool was shown to four experts in the field of FTP and survey development; these experts made suggestions as to how to improve the items.

Focus groups ( $\mathrm{n}=3$ focus groups, $\mathrm{n}=6$ participants) were conducted using the target population of sophomore engineering students. In these focus groups, students were asked to fill out the survey rating the clarity of the items. The students were then interviewed during the focus group about how they interpreted the items, what items were unclear, and why those items were unclear. The items were changed accordingly and reassessed by the experts to develop a final list of items. These items can be seen in Appendix B.

The final list of items was then compiled into a survey instrument, which also included demographic information and an option to volunteer for a follow up interview. The survey was given for course credit to a sophomore level IE course, and 187 students completed the survey. The data were cleaned and statistical software was used to run the analysis. A scree plot was used to determine the number of factors that best explain the variability in the data. The scree plot showed that the number of factors should be between three and five. An exploratory factor analysis (EFA) was run with six factors, to test if the items would factor into the intended constructs, and then run with three to five factors to find which factors best fit the data.

Those factors were then tested for internal consistency validity. A high internal consistency reliability, or how correlated the items in a factor are, can suggest that the items in each factor are measuring the same construct ${ }^{18}$. Cronbach's alpha $(\alpha)$ was used to test for internal consistency reliability for each of the factors.

A k-means cluster analysis and interviews were used to test for external consistency, or how the results of the instrument can be generalized, or replicated with other methods ${ }^{19}$. A k-means cluster analysis forms homogenous groups based on the scores from the specified factors ${ }^{18,20}$. 
This analysis will show us if students are grouping into clusters that represent each of the FTP cone types based on the factors that were developed. Additionally, interviews were conducted $(n=3)$ using the semi-structured interview protocol that was implemented in our previous qualitative work. The audio recordings of the interviews were analyzed using a priori coding, where the codes from the previous work were used to describe each of the students in one of the FTP cone types. The results from the cluster analysis and the interview analysis were compared to check how well the instrument was capturing the characteristics we can identify in interviews.

\section{Results}

\section{Factors and Items}

Several code categories emerged in our previous qualitative studies that characterized students' FTP that served as the starting point for developing factors to include in the quantitative survey. The factors were narrowed down based on what was needed to distinguish the three FTP types by creating a list of code categories that characterized each FTP cone type. Code categories that were redundant across types were identified and excluded from the survey refinement process. The final factors included in the survey, what a high score in the factors mean, abbreviations for the factor and the expected means for each cone type are listed in Table 1. The expected means for each FTP cone type are based on the results of our previous qualitative work $^{5-7,13}$.

\begin{tabular}{|l|l|l|l|l|l|}
\hline \multicolumn{5}{|c|}{ Table 1: Hypothesized Means for Each Factor within Clusters } \\
\hline \multicolumn{1}{|c|}{ Factor } & \multicolumn{1}{|c|}{ High Score Definition } & Abbrev. & Sugar & Waffle & Cake \\
\hline Depth of future goals & $\begin{array}{l}\text { The student is setting goals } \\
\text { deep (about 10 years) into the } \\
\text { future. }\end{array}$ & Depth & High & Medium & Low \\
\hline $\begin{array}{l}\text { Number of future } \\
\text { possible selves }\end{array}$ & $\begin{array}{l}\text { The student can imagine } \\
\text { many different future possible } \\
\text { selves. }\end{array}$ & Number & Low & Medium & High \\
\hline $\begin{array}{l}\text { Relationship between } \\
\text { realistic and ideal } \\
\text { future possible selves }\end{array}$ & $\begin{array}{l}\text { The student has the same } \\
\text { realistic and ideal future } \\
\text { possible selves. }\end{array}$ & Ideal & High & Low & N/A \\
\hline $\begin{array}{l}\text { Relationship between } \\
\text { realistic and avoided } \\
\text { future possible selves }\end{array}$ & $\begin{array}{l}\text { The student has the same } \\
\text { realistic and avoided future } \\
\text { possible selves. }\end{array}$ & Avoided & Low & High & N/A \\
\hline $\begin{array}{l}\text { Effect of future on } \\
\text { present }\end{array}$ & $\begin{array}{l}\text { The student believes the } \\
\text { future has a high impact on } \\
\text { what the student does in the } \\
\text { present. }\end{array}$ & FoP & High & Medium & Low \\
\hline $\begin{array}{l}\text { Perceived } \\
\text { Instrumentality }\end{array}$ & $\begin{array}{l}\text { are doing in the present as } \\
\text { useful. }\end{array}$ & PI & High & Low & High \\
\hline
\end{tabular}

There were concerns with Cake Cone respondents being able to answer the ideal and avoided items because the questions may have imposed an ideal, avoided, and realistic future possible self that the participant did not have. The means for Cake Cone students for ideal and avoided 
are listed as "Not Applicable" (N/A) for this reason and because it did not appear in the qualitative results for Cake Cone students.

The content validity of the items was improved by the experts in the field and through focus groups. One researcher pointed out that our some of our items intended to measure depth were actually measuring how well-defined students were thinking of their future. Additional items were added that appropriately measured depth. The focus groups revealed how students were interpreting the items, what items were unclear to the students, and why those items were unclear. From these focus groups we found that some words were being interpreted differently; for example, "explore" was interpreted as thinking about doing something, where "consider" meant a more active pursuit of something. The items were changed accordingly and reassessed by the experts to develop a final list of items. These items can be seen in Appendix B.

\section{Pilot}

The resulting survey was completed by students in a sophomore level IE course $(n=187)$. The results from the survey were used to test for internal consistency reliability. The EFA showed that the items did not load well into six factors. After removing items that did not load and running an EFA for three, four, and five factors, the final factors were determined to be the five described in Table 2.

Table 2: The resulting factors from the EFA and their corresponding Cronbach's alpha

\begin{tabular}{|l|l|c|c|c|}
\hline \multicolumn{1}{|c|}{ Factor } & \multicolumn{1}{|c|}{ High Score Definition } & Abbrev. & $\begin{array}{c}\text { Number } \\
\text { of Items }\end{array}$ & $\begin{array}{c}\text { Alpha } \\
(\boldsymbol{\alpha})\end{array}$ \\
\hline $\begin{array}{l}\text { Definition of } \\
\text { Future Goals }\end{array}$ & $\begin{array}{l}\text { The student has well-defined goals for the } \\
\text { future. }\end{array}$ & Definition & 5 & 0.82 \\
\hline $\begin{array}{l}\text { Depth of Future } \\
\text { Goals }\end{array}$ & $\begin{array}{l}\text { The student is setting goals deep (about 10 } \\
\text { years) into the future. }\end{array}$ & Depth & 3 & 0.71 \\
\hline Time Attitude & $\begin{array}{l}\text { The student has a positive outlook about the } \\
\text { future. }\end{array}$ & $\begin{array}{c}\text { Time } \\
\text { Attitude }\end{array}$ & 9 & 0.86 \\
\hline $\begin{array}{l}\text { Effect of Future } \\
\text { on Present }\end{array}$ & $\begin{array}{l}\text { The student believes the future has a high } \\
\text { impact on what the student does in the present. }\end{array}$ & FoP & 5 & 0.87 \\
\hline $\begin{array}{l}\text { Perceived } \\
\text { Instrumentality }\end{array}$ & $\begin{array}{l}\text { The student views what they are doing in the } \\
\text { present as useful. }\end{array}$ & PI & 5 & 0.84 \\
\hline
\end{tabular}

The items that we hypothesized would load into one depth factor, actually loaded into two factors: depth and definition of future goals. As pointed out by one of the experts in the field, some of the items intended to measure depth were actually measuring how well-defined their future goals are. The "Number" items did not load into any factor, and those items were removed. The ideal and avoided items loaded as one factor, "Attitude." Three items were removed from FoP; and PI stayed the same. The new factors and their items can be seen in Appendix C. 
Cronbach's alpha $(\alpha)$ was calculated to test for internal consistency reliability for each of the factors, and was in the acceptable range for education research of above $>0.7$ for each ${ }^{12}$. This is shown in Table 2 along with the description of factors and the number of items in each.

Finally, a k-means cluster analysis was used to group the students into three clusters based on the previous studies that identified three characteristic types of FTP. Three clusters accounted for 65.07\% of the variability. The cluster plot can be seen in Appendix D. The means of each of the factors in each cluster are shown in Table 3. The means fit with the hypothesized means, except for the Time Attitude (Attitude) and effects of future on present (FoP) factors. These clusters along with the following interviews were used to describe the instrument's external validity.

\begin{tabular}{|l|c|c|c|c|c|c|}
\hline \multicolumn{6}{|c|}{ Table 3: Mean Factor Scores within Each Cluster and for Each } \\
Interviewee as Determined by K-Means Cluster Analysis \\
\hline & Sugar & Waffle & Cake & $\begin{array}{c}\text { Nikki } \\
\text { (Sugar) }\end{array}$ & $\begin{array}{c}\text { Thomas } \\
\text { (Cake) }\end{array}$ & $\begin{array}{c}\text { Helen } \\
\text { (Sugar) }\end{array}$ \\
\hline Definition & 5 & 2.9 & 3.3 & 5.2 & 6 & 5 \\
\hline Depth & 6 & 4.6 & 4.3 & 5.33 & 7 & 7 \\
\hline Attitude & 5.7 & 4.7 & 4.3 & 5.33 & 5.89 & 5.78 \\
\hline FoP & 4.2 & 3 & 5 & 5 & 6.4 & 6.4 \\
\hline PI & 4.7 & 3.1 & 4.9 & 4.4 & 4.4 & 6 \\
\hline
\end{tabular}

\section{Nikki's Interview}

Nikki is a sophomore in BME, and she describes her future goals with definition and depth into the future. She definitely wants to work in BME, and stay in engineering. When asked if she saw herself staying in engineering and how certain she was, Nikki replied, "Oh yeah, definitely" and, "Very. Like, ten out of ten." She would like to work in tissue engineering and is working towards getting internships and experience working in tissue engineering. And, eventually, she would like to have her own patent.

Another part of her future career goal is to work abroad: "I'm willing to live abroad really anywhere." But specifically she wants to spend at least one year in Germany. She described the steps that she is taking now to reach her goals of working in BME abroad. She is currently working in a student organization that travels to developing countries and uses engineering to improve the quality of life in communities in these countries. She also wants to get an anthropology minor and study abroad to make her more qualified for a job that allows her to travel. The fact that she narrowed down her future goals and is able to describe these goals beyond her first job after graduation fits with other Sugar Cone students; however, there was not as much definition as other Sugar Cone students we have interviewed in previous studies ${ }^{5-7,12}$. She also sees these ideal future goals as realistic, as we would expect for a Sugar Cone student.

Nikki's future goals affect her actions in the present. She wants to be qualified for jobs so she has concerns about keeping her GPA high enough to be qualified for jobs. She goes on to describe that if she learns the material, she'll be able to achieve those goals even without a high GPA. This desire is driving her to work hard in her classes, particularly her classes related to tissue engineering to learn as much as possible, which is endogenous instrumentality. Her PI and 
FoP are consistent with Sugar Cone students, as well as her avoided future possible self (electrical engineering) being closely related to her ideal/realistic possible self.

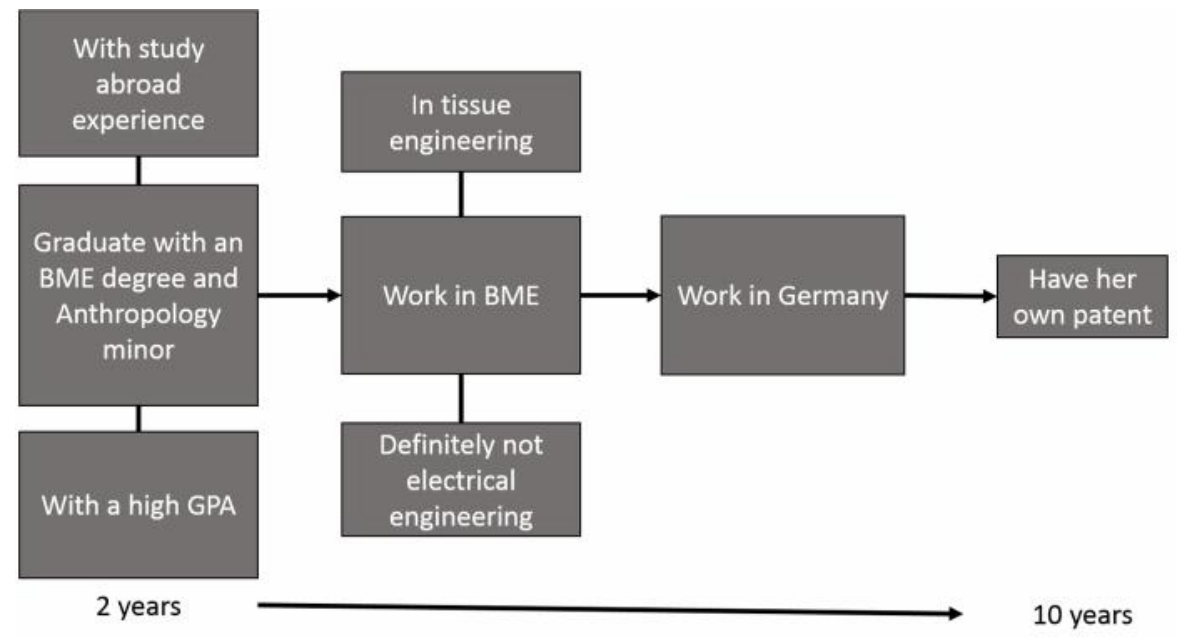

Figure 2: Nikki's perceptions of the future involve working in BME on tissue engineering, working in Germany, and having her own patent.

Her survey results (Table 3) placed her in the Sugar Cone cluster; her placement in the cluster (Appendix D) was close to the border of the Sugar and Cake Cone clusters. Her FoP scores are lower than would be expected for Sugar Cone according to the qualitative work, but this result is consistent with the mean scores in the Sugar Cone cluster from the quantitative analysis.

\section{Thomas's Interview}

Thomas is a sophomore in IE, and his main focus is graduating with his IE degree. He has a high number of future possible selves; he can see himself as a manager at a "typical" nine to five job in manufacturing, a healthcare setting, construction, business or any other IE field. This is characteristic of Cake Cone students as well as the ability to talk about characteristics of his future career without one set finite goal. His future desired possible career involves working with people, being able to help people, using his IE degree, and not having to sit at a desk all day.

When asked about any jobs he would not like to do, he was adamant about not wanting to work in fast food, and said, "I'm not really set on one thing [career]; I have like a broad spectrum, so I'm fine with going - if I have to go like a construction route, or business route, or healthcare route I'm not going to phase away from it." This quote demonstrates again his broad definition of desired future possible careers. And, the more general and less related to his field avoided self is typical of a Cake Cone student. Cake Cone students do not focus on the way the future is affecting the present, but rather focus more on how the present connects to the future. Thomas describes this: "I think the goals you set in the future can be affected by the things you do now."

Thomas's survey results, shown in Table 3, are not consistent with those for a Cake Cone student. He had high scores in definition and depth; which fits with his interview. He was able to describe with some detail his many possible future careers. However, he was placed in the Cake Cone Cluster based on where his survey response data was positioned in the cluster analysis. 


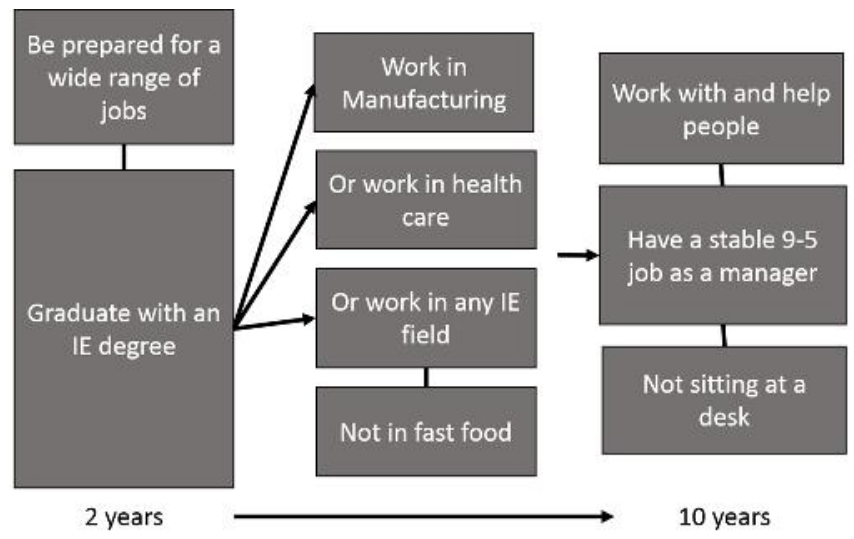

Figure 3: Thomas's perceptions of the future have a depth of 10 years, but with very little definition. He is able to describe characteristics of his job in a number of possible fields.

\section{Helen's Interview}

Helen describes her future career with definition and depth into the future, with the steps she plans on taking to reach one specific future goal; this fits with the description of a Sugar Cone student. She wants to get an IE degree, work for a consulting company (most likely with Company $\mathrm{X}$, because she has connections at that company) at the entry level then work up the management ladder. Her ideal and realistic future career is to become the CEO of a Fortune 500 company in 25 to 30 years; she describes the outcome of this future as "being successful."

She does not see her IE classes as important for her future except that they will get her an IE degree. She sees endogenous instrumentality in her management classes. Her future influences how she acts in the present - she is constantly trying to boost her resume and keep her GPA above a 3.5 because that's what companies look for. The limited endogenous instrumentality and the high FoP is consistent with a Sugar Cone. This is illustrated in Figure 4.

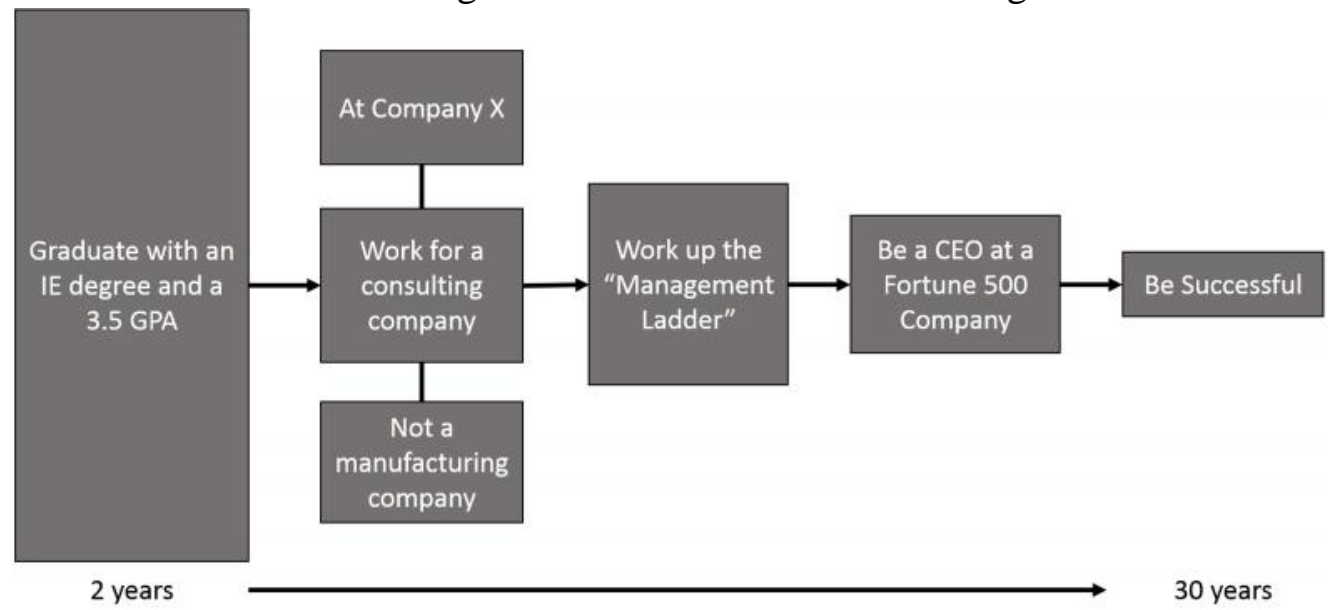

Figure 4: Helen's perceptions of the future exist up to 30 years in the future. She is working towards the goal of being a CEO of a Fortune 500 company.

Helen's survey results (Table 3) also place her in the Sugar Cone cluster. Her results from the interview align with the results from her survey, and both firmly indicate she fits in the Sugar 
Cone FTP cone type. This is also supported by her position in the cluster analysis; she falls near the middle of the Sugar Cone Cluster, as shown in Appendix D.

\section{Discussion}

Survey validity and reliability testing is a long and iterative process; this study was the first iteration with some promising results and directions for improvements for the next iterations. The EFA resulted in five factors, all with Cronbach's alphas of over 0.7 and four of which had Cronbach's alphas over 0.8. These five factors are characteristics of students' FTP cone types as identified in qualitative work; including these factors with other constructs in surveys could lead to a more robust ability to characterize students' FTP cone types. This may explain why the cluster analysis did not describe a high amount variability (65\%). Previous studies with FoP and PI constructs showed three clusters matching the expected cone types which accounted for variabilities between 70 and $89 \%{ }^{14}$. This indicates that goal orientation and the other components of FTP account for more variability. And, as with any instrument, more work remains to develop items related to the desired constructs, and to refine the wording to most closely align with students' descriptions of their experiences in the qualitative data.

The means for each of the three clusters in the k-means cluster analysis represents the three categories of FTP identified in the qualitative studies, with some discrepancies. The FoP for the Cake Cone cluster was the highest, and we would expect it to be the lowest. But none of the scores were high; each of the scores was under five on a scale of seven. Each of the other factors had at least one score over five. This discrepancy may indicate that these items were being answered more conservatively than items in other factors. However, this isn't supported by the results from the external validation. In the surveys for external validation, we found that the factors were capturing the way in which the students were describing their FTP in interviews; however, there were some concerns with how the cluster analysis was grouping these students, for example Thomas's depth and definition scores were high (6 and 7), yet, he was placed in the Cake Cone cluster. Our research group is working on exploring different clustering techniques that are more appropriate for education research that allow for a better representation of how the data are grouped.

There were also some interesting findings within the attitude scores. The attitude scores for the Sugar Cone cluster were high (5.7), as expected; Sugar Cone students believe that they can achieve their ideal future selves. Waffle Cone students believe that they will not be able to achieve their ideal future, but rather are likely to end up as their avoided future possible selves. So, we would expect the attitude scores in the Waffle Cone clusters to be low. They are lower (4.7) than the scores in the Sugar Cone cluster, and we have no qualitative comparison for how Cake Cone students would answer the attitude items, since Cake Cone students do not define an ideal possible career. It is interesting to note that the Cake Cone cluster scores were the lowest out of the three types for attitude (4.3), and that the Waffle Cone cluster attitude scores were not as low as expected.

\section{Conclusions and Future Work}


The goal of the project is to create a reliable instrument, one that consistently and accurately represents a students' characteristic FTP type. Further validity and reliability testing will help reach this goal. Recommendations for these studies include:

- Removing items from the attitude factor, which currently has nine items.

- Extending items in the depth factor from 10 years to 30 years; the depth factor in this instrument measures up to 10 years, which may not be far enough into the future for some Sugar Cones students, such as Helen.

- Conducting further focus groups and interviews to explore how students are answering the depth items; are the students answering the questions conservatively or are the items unclear?

- Completing a study with the refined MAE survey including the factors developed in this study, with a higher number of participants, for further validity and reliability testing.

Creating this survey is a starting point for getting larger amounts of data on undergraduate engineering students' motivations and connecting them to behaviors in the classroom that can improve retention and learning in undergraduate engineering programs.

Acknowledgement: The authors wish to acknowledge researcher, Justine Chasmar, and the National Science Foundation for their support of this research (EEC-105590).

\section{References}

1. Atman CJ, Sheppard SD, Turns J, et al. Enabling Engineering Student Success: The Final Report for the Center for the Advancement of Engineering Education. Final Rep Cent Adv Eng Educ. 2010.

2. A Report from the Committee on STEM Education National Science and Technology Council. Federal Science, Technology, Engineering, and Mathematics (STEM) Education: 5-Year Strategic Plan. 2013.

3. Yoder BL. Engineering by the Numbers. ASEE. 2014:11-47.

4. Kirn A, Faber C, Benson L. Engineering Student Metacognition during Dynamic Transfer in a Problem Solving Scenario. In: National Association for research in Science Teaching 2014 Annual Conference.; 2014.

5. McGough C, Faber C, Kirn A, Benson L. Connections between Undergraduate Engineering Students ' Problem Solving Strategies and Perceptions of Engineering Problems. In: ASEE Annual Conference.; 2015.

6. McGough C, Kirn A, Benson L. Relationships between Engineering Students' Future Time Perspectives and Their Problem Solving Processes. NARST Conf. 2015:1-5.

7. Kirn AN. The Influences of Engineering Student Motivations on Short-Term Tasks and Long-Term Goals. Dissertation. 2014.

8. Kirn A, Faber C, Benson L. Engineering Students Perception of the Future: Implications for Student Performance. Am Soc Eng Educ. 2014.

9. Husman J, Lens W. The Role of the Future in Student Motivation. Educ Psychol. 1999;34(July 2014):113125. doi:10.1207/s15326985ep3402.

10. Husman J, Derryberry WP, Crowson HM, Lomax R. Instrumentality, task value, and intrinsic motivation: Making sense of their independent interdependence. Contemp Educ Psychol. 2004;29:63-76. 
doi:10.1016/S0361-476X(03)00019-5.

11. Markus H, Nurius P. Possible Selves. Am Psychol. 1986;41(9):954-969.

12. Chasmar J, Benson L. Future Time Perspective and Self-Regulated Learning: Multiple Case Studies in Industrial Engineering. In: American Society for Engineering Education.; 2016.

13. Major J, Boone H, Tsugawa M, McGough C, Benson L, Kirn A. Engineering Student's Perceptions of the Future: Transferability and Replication of Time Perspective Classifications. In: National Association for Research in Science Teaching 2016 Annual Conference.; 2016.

14. Kirn A, Benson L. Engineering Students ' Perceptions of the Future : Exploratory Instrument Development. In: 122nd ASEE Annual Conference \& Exposition.; 2015.

15. Pintrich PR, Smith DA, García T, McKeachie J. W. Reliability and predictive validity of the Motivated Strategies for Learning Questionnaire (MSLQ). Educ Psychol Meas. 1993.

16. Stump GS, Husman J, Corby M. Engineering Students' Intelligence Beliefs and Learning. J Eng Educ. 2014;103(3):369-387. doi:10.1002/jee.20051.

17. Schraw G, Horn C, Thorndike-Christ T, Bruning R. Academic Goal Orientation and Student Classroom Achievement. Contemp Educ Psychol. 1995.

18. DeVellis RF. Scale Development: Theory and Applications. Sage publications; 2012.

19. Calder BJ, Phillips LW, Tybout AM. The Concept of External Validity. J Consum Res. 1982;9(3):240-244. doi:10.1086/208920.

20. Fraley C, Raftery E. How Many Clusters? Which Clustering Method? Answers Via Model-Based Cluster Analysistle. Comput J. 1998;41(8):578-588. 


\section{Appendix A: Characteristics of Each of the FTP Cone Types ${ }^{5-7}$}

\section{Sugar Cone:}

- Defined their futures with a high level of clarity, deep into the future.

- Have highly developed FTP that consist of a series of steps or paths to reach a distant future goal.

- Have limited down the number of possible future goals.

- Are able to identify which tasks possess endogenous instrumentality.

- Have avoided selves closely related to their future goals.

- Expressed desired outcomes for their future careers.

- Have an intrinsic reason to work harder, focus more, and strive for learning.

\section{Waffle Cone:}

- Define their futures with a high level of detail deep into the future.

- Did not express future goals beyond that of their first career after graduation.

- Possess ideal and attainable selves that differ from one another

- Part of their attainable self is also part of their avoided self.

- Did not express a desired outcome of their future career.

- Develop skills in the present for refinement of the future.

- Limit which tasks are viewed with endogenous instrumentality.

\section{Cake Cone:}

- Provide limited definition of their futures.

- Have difficulty connecting their futures to their present actions.

- Are able to define undesired careers.

- Able to define characteristics of jobs they do want to have.

- Did not express an ideal future.

- Have limited or no connections from the future to the present.

- Do not use their futures to create value judgments of what tasks are important.

- View all tasks as relevant to helping them define their future.

- Rely purely on the intrinsic enjoyment of learning. 


\section{Appendix B: Items Included in the Survey}

\begin{tabular}{|c|c|c|}
\hline Factor & & Item \\
\hline \multirow{6}{*}{ Number } & N1 & There are multiple careers that I can imagine being rewarding. \\
\hline & N2 & I am considering multiple careers only as a backup plan. \\
\hline & N3 & I am considering multiple careers. \\
\hline & N4 & There is only one career I can imagine that I would find rewarding. \\
\hline & N5 & Although there is only one career I really want, I have at least one back up plan. \\
\hline & N6 & I am actively looking into different careers. \\
\hline \multirow{9}{*}{ Depth } & D1 & I am unsure what I want my future career to be. \\
\hline & D2 & I have a clear idea of what my first job after graduation will be. \\
\hline & D3 & I have a clear idea of what my future career will be in 10 years. \\
\hline & D4 & I'm not exactly sure what I want to do after college. \\
\hline & D5 & I don't really have a set career goal. \\
\hline & D6 & My future career is too far off to think about now. \\
\hline & D7 & My first job after graduation is something I think about daily. \\
\hline & D8 & I do not worry about what I want to do after college \\
\hline & D9 & My future career is too far off to consider now. \\
\hline \multirow{6}{*}{ Ideal } & 11 & The career path I really want is not the career path I expect to have. \\
\hline & 12 & I will be able to follow the career path that would be the most rewarding for me. \\
\hline & 13 & The career path I would find most rewarding is not realistic for me. \\
\hline & 14 & My ideal career is different from my realistic career. \\
\hline & 15 & The career I would I ideally want is different from a career I could realistically get. \\
\hline & 16 & I believe I can obtain the career I want. \\
\hline \multirow{3}{*}{ Avoided } & A1 & I do not think I will enjoy the job I will have immediately after graduation. \\
\hline & $\mathrm{A} 2$ & The job offers I will be able to get after graduation are not the types of jobs I want. \\
\hline & A3 & I think I will be satisfied with the career I will be able to achieve. \\
\hline \multirow{5}{*}{$\mathrm{PI}$} & PI1 & I will use the information I learn in this course in the future. \\
\hline & $\mathrm{PI} 2$ & I will not use what I learn in this course. \\
\hline & $\mathrm{PI3}$ & I will use the information I learn in this course in future courses. \\
\hline & $\mathrm{PI} 4$ & My course work is preparing me for my first job after graduation. \\
\hline & $\mathrm{PI5}$ & The skills I learn in this course will be important for my future occupational success. \\
\hline \multirow{8}{*}{ FoP } & F1 & My future career determines what is important to me in this course. \\
\hline & F2 & My future career influences what I want to learn in this course. \\
\hline & F3 & I do not connect my future career to what I am learning in this course. \\
\hline & F4 & $\begin{array}{l}\text { My future career is an important consideration in how I decide to approach this } \\
\text { course. }\end{array}$ \\
\hline & F5 & My plans for my future career path do not affect the how I approach this course. \\
\hline & F6 & I think about my future career to determine what is important in this course. \\
\hline & F7 & I focus on learning information that will help be successful in my career. \\
\hline & F8 & $\begin{array}{l}\text { I do not make connections between my future career and what I am learning in } \\
\text { this course. }\end{array}$ \\
\hline
\end{tabular}




\section{Appendix C: Factors after EFA}

\begin{tabular}{|c|c|c|}
\hline \multirow{5}{*}{ Definition } & D1 & I am unsure what I want my future career to be. \\
\hline & D2 & I have a clear idea of what my first job after graduation will be. \\
\hline & D3 & I have a clear idea of what my future career will be in 10 years. \\
\hline & D4 & I'm not exactly sure what I want to do after college. \\
\hline & D5 & I don't really have a set career goal. \\
\hline \multirow{3}{*}{ Depth } & D6 & My future career is too far off to think about now. \\
\hline & D8 & I do not worry about what I want to do after college. \\
\hline & D9 & My future career is too far off to consider now. \\
\hline \multirow{9}{*}{ Attitude } & 11 & The career path I really want is not the career path I expect to have. \\
\hline & 12 & I will be able to follow the career path that would be the most rewarding for me. \\
\hline & 13 & The career path I would find most rewarding is not realistic for me. \\
\hline & 14 & My ideal career is different from my realistic career. \\
\hline & 15 & The career I would I ideally want is different from a career I could realistically get. \\
\hline & 16 & I believe I can obtain the career I want. \\
\hline & A1 & I do not think I will enjoy the job I will have immediately after graduation. \\
\hline & A2 & $\begin{array}{l}\text { The job offers I will be able to get after graduation are not the types of jobs I } \\
\text { want. }\end{array}$ \\
\hline & A3 & I think I will be satisfied with the career I will be able to achieve. \\
\hline \multirow{5}{*}{$\mathrm{PI}$} & PI1 & I will use the information I learn in this course in the future. \\
\hline & $\mathrm{PI} 2$ & I will not use what I learn in this course. \\
\hline & $\mathrm{PI3}$ & I will use the information I learn in this course in future courses. \\
\hline & $\mathrm{PI} 4$ & My course work is preparing me for my first job after graduation. \\
\hline & PI5 & $\begin{array}{l}\text { The skills I learn in this course will be important for my future occupational } \\
\text { success. }\end{array}$ \\
\hline \multirow{5}{*}{ FoP } & F1 & My future career determines what is important to me in this course. \\
\hline & F2 & My future career influences what I want to learn in this course. \\
\hline & $\mathrm{F} 4$ & $\begin{array}{l}\text { My future career is an important consideration in how I decide to approach this } \\
\text { course. }\end{array}$ \\
\hline & F6 & I think about my future career to determine what is important in this course. \\
\hline & F7 & I focus on learning information that will help be successful in my career. \\
\hline
\end{tabular}




\section{Appendix D: K-means Cluster Plot}

\section{CLUSPLOT( FTP3 )}

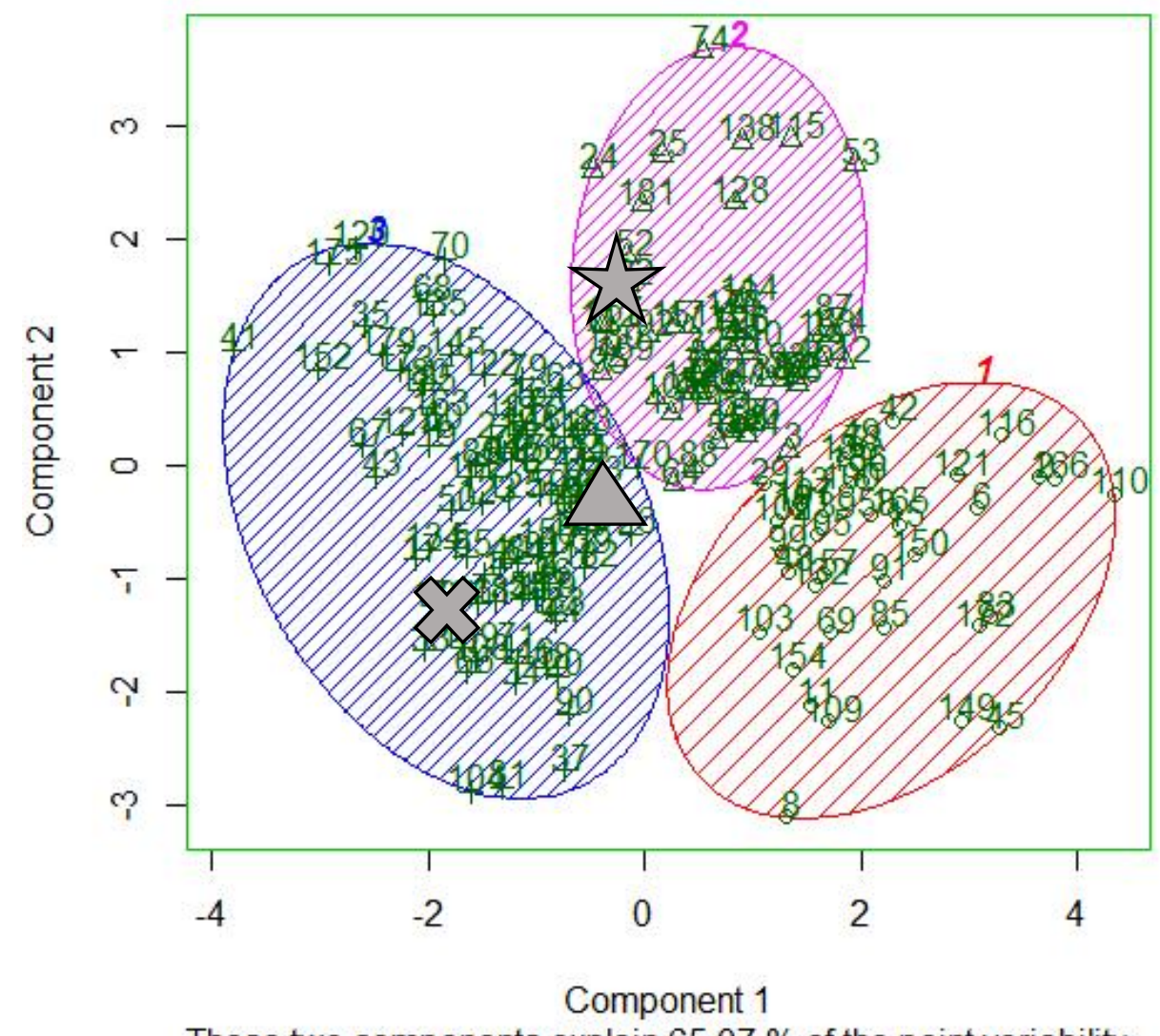

These two components explain $65.07 \%$ of the point variability.

Nikki:

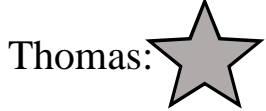

Helen: \& 